\title{
The Influence of Depressive Mood on Activities of Daily Living and Health Care Utilization in the Elderly - The MEMO Study on the KORA Platform Augsburg
}

\author{
B. T. Braune ${ }^{1}$ \\ K. Berger ${ }^{2}$
}

\begin{abstract}
Einfluss von Depression auf Aktivitäten des Alltagslebens sowie Nutzung des
Gesundheitssystems bei Älteren - Die MEMO-Studie auf der KORA-Plattform

Augsburg
\end{abstract}

\section{Zusammenfassung}

Die Depression ist ein häufiges Krankheitsbild in der Allgemeinbevölkerung und wird zudem häufig als Komorbidität bei Patienten mit bestimmten Erkrankungen gefunden. Der überwiegende Anteil bisheriger Studien hat Patientenpopulationen mit manifester, bereits diagnostizierter Depression untersucht. Es gibt nur wenige Daten darüber, inwieweit das Vorliegen einer Depression Einfluss auf die Benutzung von Gesundheitsdienstleistungen und das Alltagsleben in der älteren Allgemeinbevölkerung hat. Wir haben die Prävalenz depressiver Symptome bei 380 Teilnehmern der Augsburger Seniorenstudie, einem 1997/98 durchgeführten Nachfolgeprojekt des Augsburger MONICA-Surveys S2 (1989/90), erhoben und ihren Einfluss auf Alltagsaktivitäten und Inanspruchnahme von Gesundheitsdienstleistungen untersucht. Die Prävalenz schwerwiegender Symptome, die das Vorliegen einer manifesten Depression anzeigen, war 10,4\%. Frauen waren doppelt so häufig betroffen wie Männer. Studienteilnehmer mit einer Depression hatten eine dreifach höhere Wahrscheinlichkeit, einen Arztkontakt in den vorangehenden 4 Wochen durchgeführt zu haben. Sie waren ferner 3- bis 4-mal so häufig in ihren Alltagsaktivitäten eingeschränkt. Schlussfolgerung: In dieser Studie war das Vorliegen einer Depression mit starken Limitationen des Alltagslebens und häufigeren Arztkontakten von Betroffenen assoziiert.

\section{Schlüsselwörter}

Depression · Prävalenz · Alltagsaktivitäten · Gesundheitsdienstleistungen

\section{Abstract}

Depression has a high prevalence in the general population and is often found as a comorbid condition in patient population with specific diseases. Little is known about health care resource use and depression impact on the daily life of community dwelling elderly. We assessed the prevalence of depression among 380 participants of the Memory and Morbidity in Augsburg Elderly Study, performed in 1997/98, a follow up project of the 1989/90 Augsburg MONICA survey S2, and evaluated the association with activities of daily living and health care utilisation. The prevalence of depressive symptoms severe enough to classify for manifest depression was $10.4 \%$. Women were twice as often affected. Participants with depression had a 3-fold higher probability for general practioner visits during the preceeding 4 weeks and were 3 to 4 fold more likely to have restrictions in their daily activities.In this study depression is associated with strong impairments in the daily life and more physician contacts of those affected.

\section{Key words}

Depression $\cdot$ prevalence $\cdot$ activity of daily living $\cdot$ health care utilisation

affiliation

${ }^{1}$ University of Muenster, Dept. of Psychiatry, Mental Health Epidemiology, Münster, Germany

${ }^{2}$ University of Muenster, Institute of Epidemiology and Social Medicine, Münster, Germany

correspondence

Klaus Berger, MD, MPH - Institute of Epidemiology and Social Medicine, University of Muenster .

Domagkstraße 3·48149 Muenster ·E-mail: bergerk@uni-muenster.de

bibliography

Gesundheitswesen 2005; 67 Sonderheft 1: S176-S179 @ Georg Thieme Verlag KG Stuttgart · New York DOI $10.1055 / \mathrm{s}-2005-858236$

ISSN 0949-7013 


\section{Background}

Depression is a highly prevalent mental disease in the general population [1,2] and has a strong age dependency. It is also often found as a co-morbid condition in patients with a wide range of somatic disorders (e.g. cardiovascular diseases, renal failure, chronic pain) [3-8] and in those with other mental disorders (e. g. schizophrenia, personality disorders, addiction) [9-13]. Given the high prevalence of depression in the community rather little is known about the relationship between depression, daily functioning and health care utilisation in non-hospitalised elderly in the general population. Since depression can be difficult to diagnose, affected individuals might contact health care providers for various somatic symptoms or complaints but remain undetected. Thus, increased use of medical care might be associated with undiagnosed depression. In a previous study a set of common risk factors for depression in community dwelling elderly people was identified during a 1 year follow-up [14]. Among them were two or more clinic visits in the past month, poor self-rated health, poor cognitive status and impaired activities of daily living (ADL). Aim of our study was the assessment of the prevalence of depressive symptoms and the evaluation of their influence on activities of daily living and health care utilisation in the MEMO-Study (Memory and Morbidity in Augsburg Elderly) in Southern Germany.

\section{Methods}

The MEMO-Study (Memory and Morbidity in Augsburg Elderly) was performed 1997/98 as a follow-up project of a subgroup of the 1989/90 WHO MONICA Survey S2, Germany (Monitoring Trends and Determinants in Cardiovascular Disease) $[15,16]$ on the KORA platform (Cooperative Health Research in the Region of Augsburg) in collaboration with the Central Hospital Augsburg. MEMO examines cognitive function and cardiovascular risk factors for neurodegenerative diseases in an elderly population. The study was restricted to participants of the second MONICA survey, who were 65 years and older on 1 October 1997 and lived in the city of Augsburg. The overall response rate among those eligible was $60.6 \%$ yielding a total of 385 participants. For the presented analysis five individuals had to be excluded due to incomplete data on the Centre for Epidemiologic Studies Depression (CES-D) scale. The study was approved by the ethics committee of the University of Muenster, Germany.

\section{Measurements}

During the interview, depressed mood was measured with the Center for Epidemiologic Studies Depression (CES-D) scale, a 20-item, self-report scale designed to measure depressive symptoms experienced during the previous week [17]. It has been shown to be a valid and reliable instrument in older populations [18]. To identify respondents with a level of depressive symptomatology that is clinically relevant, the commonly used CES-D cut-off-score of 16 was applied. It has a good criterion validity for major depression [18].

Visits of study participants to a general practitioner (GP) or a specialist of any medical discipline in the 4 weeks before the interview were documented. Restrictions of activities of daily liv- ing (ADL) and instrumental activities of daily living (IADL) were assessed with an 18-item questionnaire [19]. The first group of ADLs comprised 10 different simple activities (e.g. washing, cleaning, meals, dressing etc.) and the second group (IADL) included 8 more complex activities (e. g. finances, shopping, writing, doctor visits etc). Answers to this questionnaire were subsequently dichotomized to help needed in one or more activities versus no helped needed in ADL and in IADL.

\section{Results}

Three-hundred-eighty participants were included in this analysis, $53.2 \%$ of them being males. Their mean age was 72.5 years. In Table $\mathbf{1}$ mean values of the CES-D scale are shown according to age, gender and number of co-morbidities. Higher age, female gender and having more than one co-morbid disorder were related to higher CES-D-scores. The overall 7-day-prevalence of clinical relevant depressive mood was $10.4 \%(n=40)$, with a variation by gender of $7.4 \%(n=15)$ among men and $14 \%(n=25)$ in women (Pearson's Chi ${ }^{2}$ test $\mathrm{p}<0.05$ ).

Table 2 shows percentages of participants with clinically relevant depressive mood in relation to sociodemographic factors, health care utilisation and activities of daily living. Higher proportions of depressed participants were found among women and in the two higher age groups. No significant differences between depressed and non-depressed study participants were observed for the two major disease groups of cardiovascular morbidity and co-morbid conditions related to diseases of the bones and/or joints. Summarizing the number of co-morbidities instead did not yield a significant difference either. Participants suspicious for manifest depression had higher probabilities of health care utilisation during the preceeding 4 weeks (outpatient contacts and hospital admissions). The largest difference was observed for general practitioner contacts yielding a 3-fold higher probability for those with depressed mood. Specialist visits during the preceeding 4 weeks and hospital admissions during the last 12 months did not reach statistical significance despite being higher among those with depression. High percentages of participants in the latter group reported impair-

Table 1 Centre of Epidemiologic Studies Depression Scale (CES-D): Scores according to age, gender and co-morbidity in 380 participants of the MEMO-Study Augsburg 1997/98, a follow-up study of a subsample of participants from the MONICA survey S2 (1989/90)

\begin{tabular}{llll}
\hline & & $n$ & CES-D (mean, SD) \\
\hline overall & & 380 & $8.4(6.8)$ \\
\hline age group & $65-69$ years & 104 & $7.7(6.1)$ \\
& $70-75$ years & 134 & $8.0(6.1)$ \\
& $75+$ years & 141 & $9.2(7.8)$ \\
\hline gender & female & 178 & $9.9(7.2)$ \\
& male & 202 & $7.0(6.1)$ \\
\hline co-morbidities $^{1}$ & $0-1$ & 205 & $7.6(6.2)$ \\
& $2-3$ & 149 & $9.3(7.6)$ \\
& $4+$ & 19 & $9.3(4.9)$ \\
\hline
\end{tabular}

\footnotetext{
1 any of the following diseases: stroke, myocardial infarction, cardiac arrhythmia, heart failure, hypertension, Parkinsonism, hypo-/hyperthyroidism, diabetes, operation/amputation of limbs with/without prothesis
} 
Table 2 Depressive mood according to sociodemographic factors, co-morbidities, health care utilization and activities of daily living in 380 participants of the MEMO-Study Augsburg

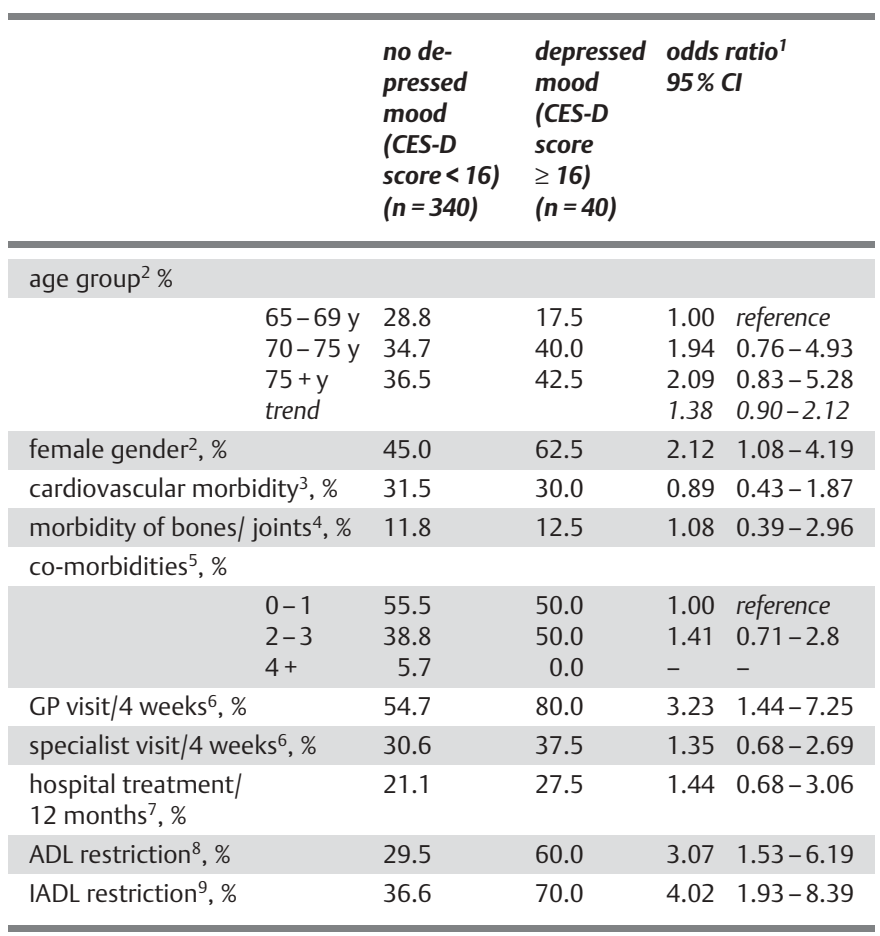

1 odds ratios derived from logistic regression models adjusted for age and gender

2 adjusted only for gender or age, respectively

3 any of the following cardiovascular diseases: hypertension, myocardial infarction, cardiac arrhythmia, heart failure

4 any of the following disease of bones or joints: operation/ amputation of limbs with/without prothesis

S178 ${ }^{5}$ co-morbidities include the listed cardiovascular and bone/joint diseases plus Diabetes, hypo-/hyperthyroidism, parkinsonism

${ }^{6}$ visits to a general practitioner or specialist during the preceeding 4 weeks

7 inpatient treatment during the preceeding 12 months

${ }^{8} \mathrm{ADL}$ : restrictions in one or more 'activities of daily living' related to toilet, dressing, washing, bathing, do one's hair/shaving, getting out of bed, cutting food, having meals, walking in flat, intake of medication

9 IADL: restrictions in one or more 'instrumental activities of daily living' related to finances/budget, doing shopping, writing letters, serving visitors, cleaning flat, do the washing, phoning, visits to GP/pharmacist/physiotherapist

ments either in simple activities of daily living or in more complex instrumental activities. Compared to those with no depressed mood participants with depression had a 3-fold higher chance to be restricted in at least one item of the basic activities and even a 4-fold chance to be limited in one or more of the eight instrumental activities.

\section{Discussion}

In this study of an elderly, general population we found a prevalence of $10.4 \%$ individuals with depressive symptoms severe enough to be suspicious for clinical manifest depression. Women were twice as often affected as men which is a common finding in community studies, even in the elderly [1, 20-22]. We observed a non-significant age dependency with higher age groups being more often affected. A high percentage of study partici- pants with depression had impairments in simple activities as well as more complex instrumental activities of daily living. This group also had higher probabilities of health care utilisation, especially visits of their general practitioner during the last 4 weeks. The latter finding is in line with studies supporting the key role for the general practitioner in the management of mental disorders [23-25].

The 7-day prevalence rate of $10.4 \%$ for clinical manifest depression in our study is about 3-fold higher than in the Australian National Survey for DSM-IV defined depression in the previous 30days [1]. Accountable for the lower prevalence in the Australian National Survey might be the applied diagnostic using the Composite International Diagnostic Interview (CIDI). A further explanation might be related to the sampling of both studies including different age groups [1].

Due to the cross-sectional study design we are unable to evaluate the sequence of depressive symptoms and impairments in activities of daily living and health care utilization. Thus, we cannot tell if in this study depressive symptoms caused impairment or if impairments due to other reasons caused depressive symptoms. In addition, a questionnaire based scoring algorhythm cannot replace the clinical diagnosis of depression. However, the questionnaire used in our study has shown high validity for manifest clinical depression if a cut off score of 16 is used.

In summary, our study results confirm those from other reports that depressive symptoms are prevalent among the elderly in the general population. Affected individuals show an increased health care utilisation and severe impairments in their daily functioning. Thus, primary health settings, especially the general practitioner or geriatric practitioner hold key roles for the detection and management of the depressed elderly patient.

\section{Acknowledgement}

The MEMO-Study is supported by the German Research Society (Deutsche Forschungsgemeinschaft, BE1996/1-1). Data assessment was done within the framework of the Cooperative Health Research in the Augsburg Region (KORA Study Group).

The article refers specifically to the following contributions of this special issue of Das Gesundheitswesen: [26-32].

\section{References}

${ }^{1}$ Wilhelm $\mathrm{K}$ et al. Prevalence and correlates of DSM-IV major depression in an Australian national survey. J Affect Disord 2003; 75 (2): $155-162$

2 Schoevers RA et al. Comorbidity and risk-patterns of depression, generalised anxiety disorder and mixed anxiety-depression in later life: results from the AMSTEL study. Int J Geriatr Psychiatry 2003; 18 (11): $994-1001$

${ }^{3}$ Beghe C, Wilson A, Ershler WB. Prevalence and outcomes of anemia in geriatrics: a systematic review of the literature. Am J Med 2004; 116 (Suppl 7A): 3S-10S

${ }^{4}$ Vazquez I et al. Psychosocial factors and quality of life in young hemodialysis patients with low comorbidity. J Nephrol 2003; 16 (6): 886 894 
${ }^{5}$ van Gool CH et al. Relationship between changes in depressive symptoms and unhealthy lifestyles in late middle aged and older persons: results from the Longitudinal Aging Study Amsterdam. Age Ageing 2003; 32 (1): $81-87$

${ }^{6} \mathrm{Lin} \mathrm{EH}$ et al. Effect of improving depression care on pain and functional outcomes among older adults with arthritis: a randomized controlled trial. Jama 2003; 290 (18): $2428-2429$

${ }^{7}$ Guo X et al. A longitudinal study on changes of movement performance and their relation to medical conditions in a female population followed from age 70 to 78 . Arch Gerontol Geriatr 2003; 36 (2): 127 140

${ }^{8}$ Goldney RD et al. Diabetes, depression, and quality of life: a population study. Diabetes Care 2004; 27 (5): 1066-1070

${ }^{9}$ de Waal MW et al. Somatoform disorders in general practice: prevalence, functional impairment and comorbidity with anxiety and depressive disorders. Br J Psychiatry 2004; 184: 470-476

${ }^{10}$ Langeland W, Draijer N, van den Brink W. Psychiatric comorbidity in treatment-seeking alcoholics: the role of childhood trauma and perceived parental dysfunction. Alcohol Clin Exp Res 2004; 28 (3): 441 447

${ }^{11}$ Cohen CI, Talavera N, Hartung R. Depression among aging persons with schizophrenia who live in the community. Psychiatr Serv 1996; 47 (6): $601-607$

12 Wetterling T, Junghanns K. Affective disorders in older inpatients. Int J Geriatr Psychiatry 2004; 19 (5): 487-492

${ }^{13}$ Szanto K et al. Identification of suicidal ideation and prevention of suicidal behaviour in the elderly. Drugs Aging 2002; 19 (1): 11 - 24

${ }^{14}$ Biderman A et al. Depression and falls among community dwelling elderly people: a search for common risk factors. J Epidemiol Community Health 2002; 56 (8): $631-636$

${ }^{15}$ Schmidt WP et al. Functional and cognitive consequences of silent stroke discovered using brain magnetic resonance imaging in an elderly population. J Am Geriatr Soc 2004; 52 (7): 1045 - 1050

${ }^{16}$ Keil U, Cairns V, Döring A et al. MONICA-Projekt Region Augsburg, Manual of Operations - Survey. GSF-Bericht 20/85, 1985.

17 Radloff LS. The CES-D scale: A self-report depression scale for research in the general population. Appl Psychol Meas 1977; (1): 385-401

${ }^{18}$ Beekman AT et al. Criterion validity of the Center for Epidemiologic Studies Depression scale (CES-D): results from a community-based sample of older subjects in The Netherlands. Psychol Med 1997; 27 (1): $231-235$

${ }^{19}$ McGauran N, Berger K, Robra BP. [Subjective need for help and objectified geriatric assess. Comparison of the Halberstadter Gerontologic Study and the Augsburger Senior Study]. Z Gerontol Geriatr 2002; 35 (1): $60-69$

${ }^{20}$ Cesari $\mathrm{M}$ et al. Prevalence and risk factors for falls in an older community-dwelling population. J Gerontol A Biol Sci Med Sci 2002; 57 (11): M722 - M726

${ }^{21}$ Harwood DG et al. Factors associated with depressive symptoms in non-demented community-dwelling elderly. Int J Geriatr Psychiatry 1999; 14 (5): 331 - 337

22 Kivela SL, Pahkala K, Laippala P. Prevalence of depression in an elderly population in Finland. Acta Psychiatr Scand 1988; 78 (4): 401 - 413

${ }^{23}$ Ress WL. The general practitioner's role in the management of psychiatric illness. J Int Med Res 1977; 5 (Suppl 1): 126-131

${ }^{24}$ Katon W, Schulberg H. Epidemiology of depression in primary care. Gen Hosp Psychiatry 1992; 14 (4): 237 - 247

25 O'Connor DW, Rosewarne R, Bruce A. Depression in primary care. 1 : elderly patients' disclosure of depressive symptoms to their doctors. Int Psychogeriatr 2001; 13 (3): 359-365

${ }^{26}$ Löwel H, Döring A, Schneider A et al. The MONICA Augsburg surveys basis for prospective cohort studies. Gesundheitswesen 2005; 67 S1: $\mathrm{S} 13-\mathrm{S} 18$

${ }^{27}$ Holle R, Happich M, Löwel H et al. KORA - A research platform for population based health research. Gesundheitswesen 2005; 67 S1: S19-S25

${ }^{28}$ Wichmann HE, Gieger C, Illig T et al. KORA-gen - Resource for population genetics, controls and a broad spectrum of disease phenotypes. Gesundheitswesen 2005; 67 S1: S26-S30

${ }^{29}$ Löwel H, Meisinger C, Heier M et al. The population-based Acute Myocardial Infarction (AMI) Registry of the MONICA/KORA study region of Augsburg. Gesundheitswesen 2005; 67 S1: S31 - S37

${ }^{30}$ Ladwig KH, Marten-Mittag B, Baumert J et al. Psychosoziale Belastungsfaktoren als Risiko für das Auftreten einer koronaren Herzerkrankung - Eine Bestandsaufnahme unter besonderer Berücksichtigung der KORA-Forschungsplattform. Gesundheitswesen 2005; 67 S1: S86-S93

${ }^{31}$ Lederbogen F, Deuschle M. Dysfunktion des Hypothalamus-Hypophysen-Nebennierenrinden-Systems - Hintergrundvariable relevanter kardiovaskulärer Risikofaktoren? Beschreibung eines kooperativen Projektes. Gesundheitswesen 2005; 67 S1: S94-S97

${ }^{32}$ Berger K, Roesler A, Kretzschmar K. The association between white matter lesions, stroke and activities of daily living - The MEMO Study on the KORA Platform Augsburg. Gesundheitswesen 2005; 67 S1: S172-S175

(1)

